\title{
Blockade of episodic gonadotrophin secretion by Immobilon in ovariectomized ewes
}

\author{
M. J. Peet and G. A. Lincoln \\ M.R.C. Unit of Reproductive Biology, 2 Forrest Road, Edinburgh, EH1 2QW, U.K.
}

Most studies on the effect of CNS depressants on pituitary gonadotrophin secretion have been of the rat. Everett \& Sawyer (1950) showed that administration of barbiturates at a critical time in the oestrous cycle could block the ovulatory surge of LH, and other CNS depressants such as morphine, reserpine and chlorpromazine have since been shown to have a similar effect (Barraclough \& Sawyer, 1955; Barraclough, 1955, 1956). The effects of these treatments can be reversed by electrical stimulation of the hypothalamus (Hagino, 1969) or by administration of LH-RH (Duncan \& Daniels, 1967). It is therefore assumed that the drugs affect the pituitary release of gonadotrophins by depressing the activity of the hypothalamus. These findings in the rat appear to apply to other species; in man, for example, heroin addiction is associated with amenorrhoea and menstrual dysfunction (Menninger-Lerchenthal, 1934; Pescor, 1938) and abnormal gonadotrophin secretion (Santen, Sofsky, Bilic \& Lippert, 1975). Robertson \& Rakha (1965) showed that ovulation in the ewe could be delayed by an injection of chlorpromazine.

There are few reports on the effects of CNS depressants on tonic gonadotrophin release. In the present study the tonic episodic secretion of $\mathrm{LH}$ and FSH were studied in ovariectomized ewes treated with a mixture of etorphine and acepromazine (Immobilon: Reckitt \& Colman, Hull). Immobilon contains etorphine hydrochloride $(2.45 \mathrm{mg} / \mathrm{ml})$ and acepromazine maleate $(10 \mathrm{mg} / \mathrm{ml})$ and was developed for immobilizing large animals in veterinary practice; it and an antidote containing diprenorphine (Revivon: Reckitt \& Colman) are commercially available. Etorphine is a highly active, synthetic morphine analogue and acepromazine maleate is a tranquillizer.

Eleven Welsh ewes, weighing approximately $50 \mathrm{~kg}$ and ovariectomized 4 months earlier, were fitted with indwelling jugular cannulae on the day before the experiment, and blood samples were collected at 15 -min intervals for $8 \mathrm{~h}$. The plasma was separated immediately and stored at $-20^{\circ} \mathrm{C}$ until assay. During sampling 3 animals received $0.25 \mathrm{ml}$ Immobilon after $210 \mathrm{~min}$ (Group 1), 3 animals received $5 \mu \mathrm{g}$ synthetic LH-RH (I.C.I., U.K.) after $330 \mathrm{~min}$ (Group 2), 3 animals received $0.25 \mathrm{ml}$ Immobilon and $5 \mu \mathrm{g} \mathrm{LH}-\mathrm{RH}$ after $210 \mathrm{~min}$ and $330 \mathrm{~min}$ respectively (Group 3), and 2 animals received $0.25 \mathrm{ml}$ Immobilon and $0.25 \mathrm{ml}$ Revivon after $180 \mathrm{~min}$ and $270 \mathrm{~min}$ respectively (Group 4). Immobilon and Revivon administration was intramuscular, and LH-RH was given as an intravenous bolus injection, flushed through the cannula with saline.

Concentrations of $\mathrm{LH}$ were determined by the radioimmunoassay of Scaramuzzi, Caldwell \& Moor (1970), using NIH-LH-S14 as the reference standard and ovine LH (LER 1374A) for radioiodination. FSH levels were measured by a heterologous radioimmunoassay with NIH-FSH-S10 as the reference standard, an antiserum raised in a rabbit against ovine FSH (NIH-FSH-S9), and a purified rat FSH preparation (NIH-Rat-FSH-I3) for radioiodination. The radioiodinations were effected by a modification of the method of Hunter, Greenwood \& Glover(1963) using Cellulose CF-11 (Whatman) for separating the iodinated hormone. Cross-reactions of the FSH antiserum with other pituitary hormones were $8.5 \%$ to ovine LH (NIH-LH-S14), $<2.0 \%$ to ovine TSH (NIH-TSH-S 8 ), $<0.01 \%$ to ovine prolactin (NIH-P-S9) and $<0.01 \%$ to ovine growth hormone (NIH-GH-11). In both assays dilutions of ovine plasma gave results parallel to those of the reference standard, and the addition of $200 \mu$ l hypophysectomized sheep plasma caused noloss of recovery over the working range of the assay. All samples from one group were checked in duplicate in the same assay and the mean intra-assay coefficient of variation was $3 \cdot 5 \%$. FSH determinations were not carried out on blood samples from animals in Group 4.

All animals treated with Immobilon (Groups 1, 3 and 4) lay down within 10 min of the injection and became deeply sedated. The animals in Groups 1 and 3 remained prostrate for more than $120 \mathrm{~min}$ 


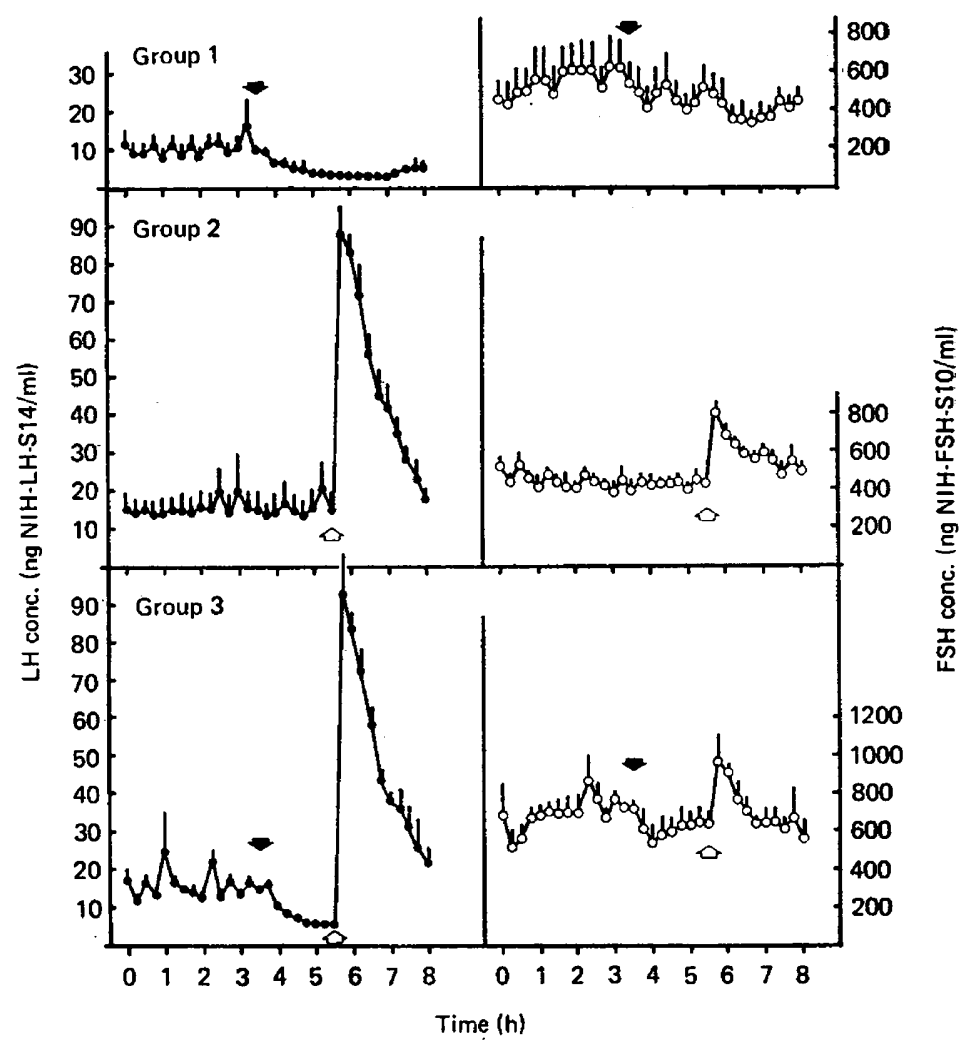

Text-fig. 1. Mean plasma concentrations ( \pm S.E.M.) of LH (e) and FSH (0) in three groups of ovariectomized ewes which received $0.25 \mathrm{ml}$ Immobilon after $210 \mathrm{~min}$ (solid arrow) and/or $5 \mu \mathrm{g}$ synthetic LH-RH after $330 \mathrm{~min}$ (open arrow).

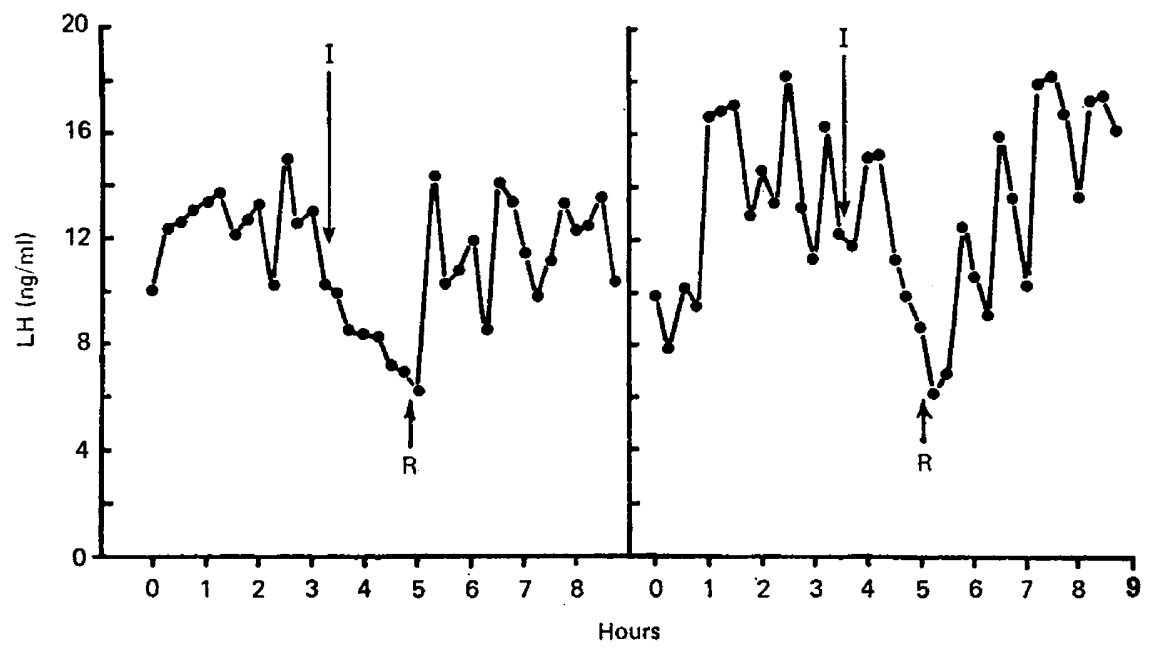

Text-fig. 2. Plasma concentrations of LH (ng equiv. NIH-LH-S14) in two ovariectomized ewes (Group 4) which received Immobilon (I) and later Revivon (R). 
and then gradually recovered consciousness; at the end of the experiment they were attempting to stand. The two animals receiving Revivon (Group 4) regained consciousness within 5 min and were soon standing again although still tranquillized. Plasma LH and FSH levels were elevated in the manner characteristic of ovariectomized ewes during the control period for all animals, and frequent small episodic peaks were seen, particularly for LH in the hormone profiles of individual animals: Immobilon abolished the episodic fluctuations in LH levels and caused a rapid decline in hormone levels, reaching significance $(P<0.001: t$ test) after $45 \mathrm{~min}$ (Text-figs 1 and 2 ). This effect was reversed by treatment with Revivon (Text-fig. 2) but otherwise persisted for at least $4 \mathrm{~h}$ (Text-fig. 1, Group 1). Plasma FSH levels also declined after the Immobilon treatment, although the decrease was slower, taking some 165 min to reach significance $(P<0.001$ : $t$-test) (Group 1). Administration of LH-RH stimulated a marked rise in LH and FSH (Groups 2 and 3 ) and there was no difference between the plasma concentrations in the sedated (Group 3) and non-sedated (Group 2) animals.

Because exogenous LH-RH was able to stimulate a normal pituitary response in the sedated animals, the decline in peripheral gonadotrophin levels caused by Immobilon appears to be due to a blockade of LH-RH release from the hypothalamus. The difference in the rates of decline for the two gonadotrophins after treatment may reflect differences in the pattern of release of the two hormones Hopkinson, Pant \& Fitzpatrick, 1974) as well as differences in the clearance rates following secretion (Kaltenbach, Schroff, Klindt \& Dunn, 1972;Akbar, Nett \& Niswender, 1974). The effect of Immobilon is immediately reversible since an injection of Revivon given during the Immobilon treatment results in a rapid return to normal LH secretion. Barraclough (1956) showed that morphine and barbiturates depress electrical activity in the reticular activating system and induce a sleep-like electro-hypothalamic record in the rat. Immobilon is likely to affect the sheep in a similar way, and suppression of endogenous LH-RH release may reflect a local effect on the neurones of the hypothalamus or a blockade of electrical stimulation from the brain centres which normally control LH-RH secretion.

We thank Dr R. J. Scaramuzzi and Dr J. Uilenbroek for their donations of the LH and FSH antisera; Dr L. E. Reichert for the LER 1374A; the Endocrine Study Section, NIH, Bethesda, for the preparations of LH, FSH, TSH, prolactin and growth hormone; and Dr J. Martinet for the hypophysectomized sheep plasma.

\section{References}

AkbaR, A.M., NetT, T.M. \& Niswender, G.D. (1974) Metabolic clearance and secretion rates of gonadotrophins at different stages of the estrous cycle in ewes. Endocrinology 94, 1318-1324.

Barraclough, C.A. (1955) Blockade of the release of pituitary gonadotrophin by reserpine. Fedn Proc. Fedn Am. Socs exp. Biol. 14, 9-10.

BARRACLOUGH, C.A. (1956) Blockade of the release of pituitary gonadotrophin by chlorpromazine. Anat. Rec. 124, 255.

Barraclough, C.A. \& Sawyer, C.H. (1955) Inhibition of the release of pituitary ovulatory hormone in the rat by morphine. Endocrinology 57, 329-337.

Duncan, G.W. \& Daniels, E.G. (1967) Bioassay of hypothalamic gonadotrophin stimulating factor. Experientia 23, 304-306.

Everett, J.W. \& SAWYER, C.H. (1950) A 24-hour periodicity in the 'LH release apparatus' of female rats disclosed by barbiturate sedation. Endocrinology 47, 198-218.

HaGINo, N. (1969) The hypothalamic time sequence controlling gonadotrophin release in the immature female rat. Neuroendocrinology 5, 1-9.

Hopkinson, C.R.N., Pant, H.C. \& Fitzpatrick, R.J. (1974) Release of LH and FSH in the normal intact ram by synthetic LH-RH and the effect of pretreatment with testosterone propionate. J. Reprod. Fert. 39, 135-139.

Hunter, W.M., Greenwood, F.C. \& Glover, J.S. (1963) The preparation of ${ }^{131}$ I-labelled human growth hormone of high specific radioactivity. Biochem. J. 89, 114-123.

Kaltenbach, C.C., Schroff, C.L., Klindt, J.M. \& DuNN, T.G. (1972) Disappearance rates of LH in hypophysectomized ewes. Biol. Reprod. 7, 135.

MENNINGER-LeRCHENTHAL, E. (1934) Schwangerschaft und Geburt morphinistischer Frauen. Zentbl. Gynäk. 58, 1044-1051.

Pescor, M.J. (1938) Statistical analysis of the clinical records of hospitalized drug addicts. Public Hlth Serv. Publs Wash., Suppl. 143, 1-30.

Robertson, H.A. \& RAKHA, A.M. (1965) The timing of the neural stimulus which leads to ovulation in the sheep. J. Endocr. 32, 383-386. 
Santen, R.J., Sofsky, J., Bilic, N. \& Lippert, R. (1975) Mechanism of action of narcotics in the production of menstrual dysfunction in women. Fert. Steril. 26, 538-548.
Scaramuzzi, R.J., Caldwell, B.V. \& Moor, R.M. (1970) Radioimmunoassay of $\mathbf{L H}$ and estrogen during the estrous cycle of the ewe. Biol. Reprod. 3, 110-119.

Received 23 July 1976 